\title{
PENGEMBANGAN MODEL PEMBELAJARAN BERBASIS STORYTELLING: SEBUAH TEROBOSAN DALAM UPAYA MENINGKATKAN OUTPUT PEMBELAJARAN BAHASA INGGRIS ANAK USIA DINI
}

\author{
Sri Setyarini \\ English Education Department \\ setyarini.engupi@yahoo.co.id
}

\begin{abstract}
ABSTRAK
Penelitian ini terfokus pada pengembangan model pembelajaran berbasis Storytelling dalam upaya meningkatkan hasil pembelajaran bahasa Inggris anak usia dini. Subyek penelitian ini adalah kelas 4A SD PN Setiabudhi. Tujuan penelitian ini adalah mengetahui jenis cerita seperti apa yang sesuai untuk siswa SD, bagaimana mengimplementasikan dan apa kendala dan solusi yang perlu diambil. Jenis penelitian ini adalah penelitian tindakan kelas yang berlangsung dalam dua siklus. Selain hasil observasi kelas sebagai hasil selama tindakan, interview kepada guru dan siswa juga dilakukan untuk mendapatkan data yang akurat yang melengkapi data dari observasi kelas. Untuk mengetahui kemampuan awal siswa dalam berbahasa Inggris, Pre-assesemen diberikan. Sebaliknya untuk mengetahui sejauhmana kemampuan siswa meningkat, mereka diberi post-assesment. Materi dalam Pre dan Post assesmen tidak sama persis tetapi beberapa soal disusun secara acak penomerannya sehingga siswa tidak dapat menghafal jawabannya. Data yang terkumpul dari beberapa sumber dianalisis dengan mengacu pada teori pembelajaran anak usia dini dan menginterpretasikannya. Hasil analisis kemudian dideskripsikan untuk menjawab beberapa pertanyaan penelitian. Secara umum, temuan penelitian ini menunjukkan bahwa Storytelling dapat dijadikan salah satu alternatif dalam meningkatkan hasil pembelajaran bahasa Inggris bagi siswa SD. Hal ini dikarenakan model ini dapat menawarkan banyak kesempatan kepada siswa untuk berlatih berkomunikasi dalam bahasa Inggris.Namun demikian, ada beberapa kendala yang masih dihadapi oleh guru dalam menerapkan metode ini, diantaranya: bahan cerita yang masih terbatas, tidak memadainya waktu untuk pelajaran bahasa Inggris, kelas yang besar, dan target pencapaian materi yang ditentukan oleh kurikulum dan silabus membuat guru kurang leluasa dalam menerapkan metode ini. Mempertimbangkan kendala tersebut, mereka mengajukan beberapa solusi yaitu:membuat sistem co-teachers dengan dosen EYL(English for young learners), penambahan jam pelajaran, meningkatkan sarana dan prasarana, dan partisipasi aktif dari stakeholders.
\end{abstract}

Kata kunci: storytelling, pre-assesmen, post-assesmen,solusi,inovasi, fun

\begin{abstract}
This research is focus on the development model learning based on storytelling in effort to increase the learning result of English language for preschool children. The subject of this research is 4A grade students of SD PN Setiabudhi. The purpose of this research is to know the kind of what story that is appropriate for the students of elementary school, how to implement it, and what is the barrier and solution that must be taken? The kind of the research is class action research which has two cycles. Beside the result of observation as the result during action, interview to teacher and students is also done to get the accurate data that complete the data from class observation. To know the early ability of students in English languages, pre- assessment is given. Otherwise to know how far the increasing of student's ability, they are given a post-assessment. The material in Pre and Post assessment are not absolutely same, but some questions are arranged randomly its numbering so the students are not memorize for its answers. The data was compiled from some source is analyzed by focus on the learning theory for preschool students and interpreting it. The analysis result then is described to answer some research questions. Generally, the invention of the research showed that storytelling is able to become one of alternative in increasing learning outcomes of English languages for the student of elementary school. It is because this model can make more chance for students to get practice in communication in English. However, there are some barriers that is still faced by teacher in implementing the method of big class, and the target of material achievement which is determined by curriculum and syllabus made teacher felt lack unhampered in implementing this method. Concerning that barriers, they submitted some solution, were: co-teacher system by EYL (English For Young Learner) Lecturer, the addition of time allocation, increasing structure and infrastructure, and active participation from stakeholders.
\end{abstract}

Keyword: storytelling, pre-assesmen, post-assesmen, solution, inovation, fun. 


\section{PENDAHULUAN}

Selama ini, banyak strategi pengajaran Bahasa Inggris untuk anak usia dini sudah diterapkan di berbagai sekolah. Namun tampaknya hingga kini, output (luaran) pembelajaran mata pelajaran tersebut belum terlihat menggembirakan. Paper ini menyajikan hasil penelitian tentang Pengembangan model pembelajaran berbasis "Storytelling" sebagai upaya dalam meningkatkan hasil pembelajaran bahasa Inggris siswa SD.

Perumusan Masalah; Agar terfokus pada masalah yang diteliti, topik penelitian ini dapat dirumuskan dalam bentuk kalimat tanya seperti berikut ini: (a) Seperti apa model cerita yang sesuai untuk siswa SD?; (b) Bagaimana model pembelajaran cerita tersebut diimplementasikan dalam proses pembelajaran?; dan (c) Kendala apa yang muncul dan apa solusinya?

Tujuan Penelitian; Untuk menjawab beberapa pertanyaan di atas, penelitian ini bertujuan untuk: (a) Mengetahui model cerita yang sesuai untuk siswa SD; (b) Mengetahui cara untuk mengimplementasikan model pembelajaran berbasis cerita kepada siswa SD; dan (c) Mengidentifikasi masalah dan mencari solusi yang tepat untuk perbaikan.

Tinjauan pustaka dalam kegiatan ini adalah:

a) Pengajaran Bahasa Inggris untuk Anakanak

Pengajaran bahasa Inggris untuk anak usia dini dalam konteks Indonesia adalah pengajaran bahasa Inggris untuk anak usia pra sekolah hingga kelas 6 SD. Pengajaran bahasa Inggris untuk anak usia dini memiliki prinsip-prinsip yang berbeda dengan pengajaran bahasa Inggris terhadap remaja ataupun orang dewasa.

Hal ini tentu saja dipengaruhi di antaranya oleh tingkat perkembangan intelektual, minat, kebutuhan, dan lingkungan. Oleh karena itu, guru yang menangani hal tersebut seharusnya memperhatikan aspek-aspek yang berhubungan dengan proses pengajaran dan pembelajaran bahasa Inggris untuk anak-anak di sekolah dasar di antaranya metode, media dan assessment yang ramah anak. Salah satu metode yang menarik dan diyakini bisa mendukung pencapaian luaran pembelajaran adalah storytelling.

b) Karakteristik Pembelajar Usia dini

Setiap pembelajar memiliki karakteristik yang berbeda. Menurut Nagy (2003), pembelajar usia dini adalah siswa yang berusia antara empat sampai dua belas tahun. Dengan kata lain bisa dikatakan bahwa semua siswa kelas 1 SD sampai kelas 1 SMP dapat diklasifikasikan sebagai pembelajar usia dini.

Musthafa (2003) mendeskripsikan karakteristik pembelajar usia dini sebagai berikut: (a) lebih efektif jika diberi materi yang sesuai dengan usianya; (b) lebih menyenangi kegiatan fisik; (c) memiliki ketertarikan pada apa yang dihadapi dan dirasakan sekarang (kini dan di sini); (d) memiliki rentang perhatian yang pendek dibandingkan dengan orang dewasa; dan (e) belajar secara implisitakuisisi.

Karakteristik tersebut dilengkapi oleh Williams (1991) yang menyebutkan beberapa karakteristik siswa usia dini diantaranya: (a) anak-anak dapat menjustifikasi pilihan dan pendapatnya; (b) rentang perhatian yang terbatas menyebabkan mereka terlatih dengan aktifitas yang singkat, bervarisi, menarik, motivatif dan nyata; dan (c) Kurikulum 2006.

Pada prinsipnya, kurikulum bahasa Inggris sebagai mata pelajaran muatan lokal (mulok) mempunyai dua komponen dasar yaitu: Standar Kompetensi (SK) dan Kompetensi Dasar (KD). Standar Kompetensi terdiri dari empat (4) ketrampilan berbahasa yaitu: membaca, mendengar, berbicara, dan menulis. Setiap ketrampilan berbahasa tersebut dideskripsikan dengan jelas mengenai cakupan kompetensi yang harus dicapai siswa. Contoh: satuan kompetensi Membaca (Reading) kelas 6, semester II 
adalah memahami teks fungsional pendek dan deskriptif bergambar sangat sederhana dalam konteks sekitar peserta didik. Setiap satuan kompetensi memiliki satu kompetensi dasar (KD). Kompetensi dasar untuk ketrampilan membaca adalah membaca nyaring teks pendek dengan ucapan dan intonasi yang tepat. Oleh karena itu, storytelling dapat dijadikan alternatif model pembelajarannya.

\section{d) English for Young Learners (Bahasa Inggris untuk anak usia dini)}

Secara umum, banyak faktor yang mempengaruhi keberhasilan siswa dalam belajar bahasa Inggris sebagai bahasa Inggris di Indonesia. Krashen (1978) dan Asher\&Price (1977) menyatakan bahwa usia dini bukanlah faktor penentu kefasihan dalam berbahasa Inggris (Ellis, 1994).

Ada beberapa faktor yang mempengaruhi kefasihan anak dalam berbahasa Inggris diantaranya waktu, jenis teks nya, gurunya, bicara, tugas dan bentuk tesnya. Namun demikian, diantara ke enam faktor tersebut, guru dan materi cenderung lebih berpengaruh terhadap keberhasilan (output) pembelajaran untuk anak usia dini. Selain itu, efektifitas pembelajaran bahasa Inggris ditentukan bagaimana guru memilih metode pengajaran yang responsif terhadap kebutuhan siswa dan sejauhmana materi ajar dapat menfasilitasi proses pembelajaran mereka. Dengan demikian, kedua aspek ini perlu mendapat perhatian oleh para pemerhati pendidikan anak usia dini, khususnya guru bahasa Inggris pada tingkat sekolah tersebut.

\section{e. Storytelling (Mendongeng)}

Mengajar melalui Storytelling atau mendongeng dalam konteks pengajaran di Indonesia bukanlah strategi pengajaran yang baru dan asing bagi para pendidik, khususnya guru SD. Mendongeng, salah satu tradisi atau budaya lisan ini sudah lama berlangsung secara turun temurun. Namun sayangnya, di zaman serba global ini, tradisi mendongeng secara perlahan mulai ditinggalkan dan tergantikan oleh tradisi menonton $\mathrm{TV}$, main games, atau permainan lainnya yang lebih mengasyikkan. Terlepas dari kelebihan dan kelemahan metode mendongeng, baik mendongeng ataupun menonton, bisa dikatakan mengandung tradisi lisan yang menunjukkan bahwa pada dasarnya manusia memang senang bercerita dan mendengarkan cerita (story).

Manfaat dan popularitas metode story telling ini dapat dimanfaatkan dalam proses belajar mengajar dalam semua tingkatan siswa, khususnya untuk siswa usia dini (SD). Salah satu manfaat yang bisa diperoleh dalam pengajaran bahasa adalah karena kisah yang diceritakan menyediakan konteks yang bermakna ketika bahasa tersebut digunakan. Berbeda dengan pengajaran grammar ataupun kosa kata (vocabulary) yang biasa diajarkan secara terpisah dari konteksnya, melalui story telling, grammar dan kosa kata bisa dipelajari secara menyeluruh dan natural

Kelebihan lain dari metode mendongeng ini adalah low cost (murah) karena pengajaran melalui storytelling tidak memerlukan peralatan yang mahal dan canggih yang terkadang sulit diperolehnya. Guru bisa menjadi media yang multifungsi dengan memanfaatkan gerak tubuh dan mimik untuk membantu siswa memahami isi cerita tersebut.

Cameron (2001) mengatakan bahwa storytelling merupakan kegiatan lisan yang dirancang bukan hanya untuk didengarkan tetapi juga untuk terlibat di dalamnya. Kontak mata yang intensif dengan siswa dan dialog yang terjadi antara guru-siswa merupakan aset unik dalam storytelling karena perilaku demikian merupakan perilaku nyata dan alami dalam berkomunikasi, dalam hal ini antara guru sebagai pendongeng dan siswa sebagai pendengar. Efeknya akan sangat berbeda apabila siswa hanya mendengarkan kaset karena hal tersebut memposisikan 
siswa sebagai pihak yang 'mencuri dengar' (eavesdropper) dan tidak terlibat di dalamnya (Morgan \& Rinvolucri, 1983).

\section{f. Pemilihan Cerita}

Yang paling penting ketika memilih cerita untuk digunakan di dalam kelas adalah berdasarkan kesukaan guru. Jika guru tidak menyukai kisah yang akan diceritakan di dalam kelas maka ia pun akan kesulitan untuk menceritakannya karena dia tidak akan menikmati ketika menceritakannya (Wright, 2003). Yang kedua, sebuah kisah dipilih berdasarkan kemungkinan siswa menyukainya karena kisahnya menghibur dan menantang (Morgan\&Rinvolucri, 1983). Ketiga, sebuah kisah dipilih karena relevan dan menyenangkan bagi siswa untuk mempelajari bahasa Inggris (Ellis, 1991 \& Cameron, 2001).

Selain itu, kriteria lain yang bisa digunakan dalam memilih cerita adalah berdasarkan tiga model sebagaimana disarankan oleh Carter \& Long (1991) yaitu: 1) model bahasa yang berkenaan dengan kosa kata dan grammar; model budaya yang berkenaan dengan informasi mengenai kehidupan dalam perspektif bahasa target yang sedang dipelajari; dan model perkembangan diri yang berfokus pada aspek psikologi dan sosial.

\section{g. Penggunaan Bahasa dalam Cerita}

Bahasa yang digunakan dalam kisah anakanak menawarkan kesempatan yang sangat banyak untuk pembelajaran bahasa, salah satunya paralelisme, kosa kata, dan naratif/ dialog (Cameron, 2001).

\section{Paralelisme}

Paralelisme berkenaan dengan pola pengulangan bahasa (Cameron, 2001). Lihat lampiran sebagai contoh. Pola berulang ini dapat merangsang pembaca untuk menebak ungkapan yang akan muncul selanjutnya serta dapat memperoleh kosa kata dan atau grammar untuk jangka lama (Kolsawalla,
2001).

Kaya akan Kosa kata

Ellis (1991) dan Cameron (2001) percaya bahwa kosa kata dalam cerita ditampilkan melalui konteks yang jelas, dibantu oleh pola peristiwa, bahasa dan gambar yang mudah diduga. Selain itu, kejelasan makna suatu kosakata dapat terbentuk dengan adanya penggunaan mimik, gerak dan bahasa tubuh yang diperagakan guru.

Oleh karena itu, anak-anak dapat dengan lebih mudah memahami makna kosakata tersebut. Bahkan untuk semakin menguatkan pemahaman ini, anak-anak bisa diajak serta untuk meniru gerakan/tindakan yang dilakukan guru. Prinsip ini mirip dengan prinsip yang ada dalam konsep Total Physical Response yang diusung oleh Asher (Cameron, 2001) yaitu listening (menyimak) dan melakukan tindakan dapat membantu anak-anak memperoleh bahasa target.

\section{Naratif/Dialog}

Pada umumnya, sebuah cerita biasanya memiliki dua bentuk penggunaan bahasa yaitu naratif dan dialog (Cameron, 2001). Naratif berisikan serangkaian peristiwa yang biasanya ditampilkan dengan menggunakan past tense sedangkan dialog menggunakan present tense form. Penggunaan past tense dalam sebuah cerita merupakan fitur alami yang tidak akan mengganggu pemahaman anak-anak terhadap isi cerita (Ellis, 1991 \& Cameron, 2001). Namun sebaliknya penggunaan past tense di dalam cerita tersebut memberikan pajanan yang kontekstual bagi anak-anak.

h. Teknik-teknik yang dapat digunakan di dalam kelas

Masalah utama yang perlu diperhatikan sebelum melakukan storytelling dalam bahasa Inggris adalah classroom management.

1. buatlah anak-anak merasa nyaman dengan pengaturan tempat duduk yang dekat dengan guru agar gerakan guru 
ataupun buku yang dipegang guru dapat terlihat dan suara guru dapat terdengar jelas.

2. gunakan alat bantu audio-visual, seperti benda-benda nyata yang otentik, boneka, gambar, topeng, dll.

3. ajarkan formulaic language pada anak seperti

- simple greeting: hello! How are you?/I'm fine, thank you. And you?

- Social English: Did you have a nice weekend?/Have a nice weekend!

- Routines: What's the date?

- Classroom languages: Listen! Repeat! Sit down! Work in pairs! Good! It's your turn! Be Quite!

Kedua, perhatikan tahap kegiatan awal sebelum storytelling. Kegiatan ini sangat krusial untuk diadakan karena anak-anak perlu mengenal terlebih dahulu hal-hal yang akan mereka temui di dalam cerita. Tahap persiapan ini bisa berlangsung selama satu pertemuan penuh atau bahkan lebih untuk memperkenalkan isi cerita, bahasa dan konsep yang termuat dalam cerita.

1. bila memungkinkan, ingatkan anak pada cerita yang telah mereka ketahui yang isinya mirip dengan kisah yang akan diceritakan atau ingatkan kisah yang banyak dipublikasikan dalam versi bahasa Indonesia. Misalnya cerita tentang Putri Salju dengan Snow White.

2. beri kegiatan yang terkait dengan pengalaman anak. Misalnya bertanya jawab tentang makanan favorit mereka, atau menceritakan pengalaman anak pergi ke kebun binatang.

3. ceritakan sinopsis atau garis besar kisah yang akan didongengkan, jika perlu dalam bahasa Indonesia.

4. ajarkan beberapa kosa kata kunci dan/ atau pola kalimat yang ada dalam cerita dengan teknik yang tepat. Misalnya, anda akan menceritakan sebuah kisah yang di dalamnya melibatkan makanan. Tunjukkan sebuah gambar dan bertanya, "Puspa, do you like sausages?" Saat itu anak bisa jadi hanya menjawab "yes" atau "no". Lakukan kegiatan serupa pada beberapa anak lainnya. Kemudian pada seluruh kelas katakan, "Now listen! Yes, I do. Repeat!". Lakukan prosedur yang sama untuk memperkenalkan "No, I don't."

5. revisi kosakata dan/atau grammar yang sudah dipelajari sebelumnya dengan teknik yang tepat.

6. agar anak lebih termotivasi, informasikan pada anak mengenai aktivitas yang akan mereka lakukan setelah mendengarkan cerita. Misalnya, membuat topeng, menulis buku cerita, memasak, bermain peran, dll.

Storytelling merupakan alat yang tidak mahal namun sangat potensial untuk menumbuhkan minat belajar bahasa Inggris pada anak-anak. Interaksi yang terjadi antara guru dan anak cenderung lebih bermakna dan alami. Kosa kata dan pola struktur kalimat yang ada dalam cerita dapat dieksploitasi sedemikian rupa untuk pembelajaran bahasa karena bahasa ditampilkan melalui konteks yang jelas.

Namun demikian, keunikan dan keajaiban yang merupakan jiwa sebuah cerita jangan sampai ternodai dengan eksploitasi penjelasan pola kalimat yang berlebihan agar anak-anak tetap memiliki kesempatan yang seluas-luasnya untuk mengapresiasi sebuah cerita dan mengalami sendiri keajaiban yang dibawa sebuah cerita dan pendongeng ke dalam kelas.

\section{METODE PENELITIAN}

Sebagai penelitian kelas, penelitian ini berlangsung selama 2 siklus. Masing2 siklus berlangsung 2 minggu, sehingga penelitian ini 
berlangsung selama kurang lebih 1 bulan (4 minggu). Setiap siklus disiapkan seluruh komponen pembelajaran berbasis storytelling. Untuk melengkapi data yang diperoleh dari observasi kelas (selama implementasi model). Data yang terkumpul kemudian dianalisis dengan mempertimbangkan prinsip-prinsip pembelajaran bahasa Inggris untuk siswa usia dini.

\section{HASIL DAN PEMBAHASAN}

Analisis data dilakukan dengan menampilkan hasil Pre-assessment dan Post-assessment serta membandingkan hasil dari keduanya. Mempertimbangkan peningkatan hasil asesmen secara signifikan menunjukkan bahwa storytelling dapat menjadi inovasi dalam meningkatkan hasil pembelajaran siswa SD. Selain itu, hasil analisis data observasi menyatakan bahwa pengembangan cerita dapat dilakukan oleh guru yang bersangkutan dengan mengacu pada topik yang tercantum pada silabus mata pelajaran bahasa Inggris. Cerita yang dikembangkan oleh guru cenderung lebih mudah dimengerti oleh siswa sehingga mereka dengan mudah mengingat kosa kata dan menyusun beberapa kosa kata atau frase dalam kalimat yang sederhana. Hasil wawancara terhadap siswa menunjukkan bahwa siswa senang dengan metode Storytelling karena suasana kelas lebih kondusif dengan aktifitas kelas beragam dan asyik. Menurut mereka dengan teknik ini, mereka lebih mudah mengenal kosakata baru, arti dan maknanya karena kosa kata tersebut diucapkan berulang-ulang oleh gurunya selama bercerita. Sebaliknya, hasil analisis data dari wawancara terhadap guru bahasa Inggris kelas 4A menunjukkan bahwa metode bercerita pada dasarnya disenangi siswa dan tampak lebih efektif daripada metode lainnya karena siswa dapat belajar lebih banyak kosa kata baru dengan mudah karena kata-kata tersebut diucapkan secara berulang-ulang dengan ekspresif. Oleh karena itu, guru tampaknya tidak perlu lagi menerangkan arti kosa kata satu persatu terpisah dengan konteks dan isi ceritanya. Namun demikian, hasil analisis data dari wawancara guru menerangkan bahwa ada beberapa kendala yang dihadapi dalam mengimplementasikan cerita diantaranya: kesulitan mencari bahan cerita yang sesuai untuk anak, kesulitan guru dalam menjiwai cerita lewat suara, mimik, dan gerakan tubuh, jam pelajaran yang tersedia sangat terbatas (1 x seminggu x 75 menit), target pencapaian materi yang sudah diatur dalam kurikulum dan silabus membuat guru kurang leluasa dalam menerapkan berbagai strategi pengajaran, dalam hal ini metode Storytelling.

\section{KESIMPULAN}

Dari temuan penelitian ini, beberapa hal bisa disimpulkan sebagai berikut:

1. Pengembangan model cerita dapat dilakukan dengan membuat sendiri dengan mengambil topik yang tercantum pada silabus. Cerita dengan tema yang sesuai dengan usia siswa dapat meningkatkan motivasi siswa untuk belajar. Cerita yang sesuai ini akan mempermudah siswa memahami isi cerita dan kosa katanya. Dengan kata lain, Storytelling merupakan metode yang sesuai untuk meningkatkan hasil pembelajaran (learning outputs) bahasa Inggris siswa SD. Peningkatan luaran pembelajaran ini dapat dilihat dari perolehan angka yang sudah dicapai oleh siswa kelas 4A setelah 3 kali mendapatkan treatment dengan implementasi pengembangan model pembelajaran berbasis cerita. Peningkatan hasil pembelajaran cukup signifikan dengan melihat hasil post-assessment yang dicapai siswa. Dalam hal ini siswa mampu menggunakan kosa kata yang sudah mereka peroleh dari cerita yang diberikan dari gurunya. Bahkan sebagian siswa mampu merangkai kalimat 
sederhana dalam bentuk cerita yang sederhana pula.

2. Ada beberapa kelebihan/keunggulan metode storytelling yang dirasakan oleh guru yaitu: siswa lebih termotivasi belajar bahasa Inggris, asyik, lebih mudah memahami pelajaran, fun, dan suasana kelas yang kondusif dengan beragam aktivitas menarik. Siswa bisa bereksplorasi dengan beragam kegiatan dan kreativitas sehingga mereka mendapatkan pengalaman dalam menggunakan bahasa tentang topik yang sedang mereka pelajari.

3. Beberapa kendala yang dihadapi guru dalam mengimplementasikan metode storytelling yaitu: sulitnya mencari cerita yang pas untuk anak, belum mengenal kriteria cerita yang sesuai untuk anak, kurang percaya diri untuk menyusun cerita anak sendiri, tersedianya waktu yang sangat sempit(75 menit seminggu 1x), kelas yang besar, sarana dan prasarana yang masih terbatas, sistem target yang sudah ditentukan dalam kurikulum dan silabus.

4. Beberapa solusi ditawarkan oleh guru yaitu dengan co-teachers, penyediaan sarana dan prasarana, peningkatan kompetensi guru melalui pelatihan dan networking dengan dosen pengajaran bahasa Inggris usia dini.

\section{DAFTAR PUSTAKA}

Annamaria. P. Teaching Young Language Leaners. 2006. Oxford University Press.

Allington, R.L "What I've learned about Effective Reading Instruction": From a Decade of Studying Exemplary Classroom Teachers' in Phi Delta Kappan, 83, (10):740-747.

Brumfit, C.,J. Moon, J.R. Tongue(eds).19984. Teaching English to Children. From Practice to Principle. London. Nelson.

Cameron, L.2001. Teaching Languages to Young Learners. Cambridge: Cambridge
University Prerss.

Caroline. T. Linse. Practical English Language Teaching Young Learners. 2005. Mc Graw_Hill

Carol Barhat M.Theories of Childhood.2000. Redleaf Press.

Corner, C.1998. Assesment in Action in the Primary School.London. Falmer Press

Cook, V.1991. Second Language Learning and Language Teaching. London. Routledge.

David Nunan,1989. Designing Tasks for the Communicative Classroom. Cambridge University Press.

Ellis, R.1994. The Study of Second Language Acquisition. Oxford: Oxford university Press.

Grace, C.E. and K. Charner.1998. The Fortofolio Book. Beltsville, MD: Gryphon House.

Halliwell, S.1992. Teaching English in the Primary Classroom. Harlow: Longman.

Justice, L.M., Meier, J.\& S.Walpole (2005). “Learning new Words from Storybooks: an Efficacy Study With at-risks Kindergarters.

Janet. K. O. Growing Up wih English. 1999. Office of English Language Program. Washington. DC.

Kasihani Suyanto (1998).Penelitian Tindakan Kelas. Jakarta. Proyek Pengembangan Pendidikan Guru Sekolah Dasar dan Menengah, Ditjen Dikti.

Kasihani Suyanto (2003). Contextual Teaching and Learning. Proyek Peningkatan Mutu SLTP.

Lowe, R. and F. Target.1998. Helping Students to Learn. London. Richmond

Linda Darling H. Preparing Teachers for A Changing World.2005.Jossey Bass.USA.

Moon, J. and M. Nikolo.(eds).2000. Research into Teaching English to Young Learners. Boston: Addison. Wesley.

Musthapa. B. Biarkan Anak-Anak Bermain. Englishiana Journal. Edisi Februari 2008.

Musthapa. B.2003. EFL for Young Learners. Due Like Project. Jakarta.

Pinter, A.2006. Teaching Young Language Learners. Oxford. Oxford University Press

Sophie Loannou G \& Pavlos Pavlou. Assessing Young Learners. 2003. Resource Books For Teachers. Oxford University Press. 
Smith, K.1997. Assesing and Testing Young Leaners. Whitstable. IATEFL

Todd,S.H.M.2003. "Know Your Grammar: What the Knowledge of Syntax and Morphology in an L2 reveals about Critical Periods for second/Foreign Language Acquasition" in M.PP.G. Mayo \& M.L.G. Lecumberri(eds). Age and the Acquisition of English as a Foreign Language. Multilingual Matters 59-73.Language.

Weir, C. 1993. Understanding and Developing Language Tests. Prentice Hall. 